\title{
Gestão de processos aplicada à realização de convênios internacionais bilaterais em uma instituição de ensino superior pública brasileira
}

\author{
Everson Mückenbergera*, Gustavo Benjamin Togashi ${ }^{\text {b, }}$ \\ Silvia Inês Dallavalle de Pádua ${ }^{c}$, Irene Kazumi Miura ${ }^{d}$ \\ a*everson@unasp.edu.br, UNASP e FEARP/USP, Brasil \\ bgutogashi@yahoo.com, FEARP/USP, Brasil \\ cdallavalle@fearp.usp.br, FEARP/USP, Brasil \\ dikmiura@gmail.com, FEARP/USP, Brasil
}

\begin{abstract}
Resumo
As possibilidades da globalização têm proporcionado a intensificação do processo de internacionalização na educação superior. Tal processo é caracterizado por complexidade e dificuldades de gestão. Uma abordagem de gestão recomendada para processos complexos é a gestão de processos de negócio (BPM). Este estudo objetiva contribuir através da avaliação e proposta da aplicabilidade do BPM na internacionalização de uma instituição de ensino superior (IES) pública brasileira. 0 estudo restringiu-se ao processo de realização de convênios bilaterais internacionais da escola de negócios de um dos campi da instituição. 0 processo de convênios bilaterais foi modelado em sua forma vigente e, a partir da análise desse modelo, foram propostas melhorias, um novo modelo e indicadores de desempenho.
\end{abstract}

Palavras-chave

Internacionalização do ensino superior. Gestão de processos de negócio. Modelagem de processos.

\section{Introdução}

Uma economia globalizada demanda profissionais com visão e sensibilidade para questões internacionais. Essa visão e sensibilidade devem ser desenvolvidas também entre os profissionais de negócios, preferencialmente desde a sua formação (SHETTY; RUDELL, 2002). Um ensino superior que seja globalizado em suas propostas de cursos e formas de gestão em muito pode contribuir para a formação desses profissionais (KNIGHT, 2006). É diante desse contexto que a internacionalização do ensino superior tem se revestido de importância cada vez maior.

Há uma relação de interdependência entre globalização e internacionalização. Enquanto a internacionalização implica em desenvolver atividades além fronteiras, a globalização promove a integração e fluxo de atividades internacionais (GEREFFI, 1999). Não haveria globalização sem atividades além fronteiras (internacionalização), e a maior facilidade no fluxo e a integração dessas atividades (globalização) tornam as atividades além fronteiras ainda mais acessíveis e atrativas. Portanto, a internacionalização do ensino superior pode ser compreendida tanto como um elemento catalisador quanto uma resposta à globalização (MIURA, 2006).

Para Knight (2003, p. 2), internacionalização do ensino superior é

[...] o processo no qual se integra uma dimensão internacional, intercultural ou global nos propósitos, funções e oferta de educação pós-secundária. (grifo nosso).

Portanto, a internacionalização de uma instituição de ensino superior (IES), entendida como um processo, ocorre na medida em que se realiza "[...] um conjunto definido de atividades ou comportamentos executados 
por humanos ou máquinas [...]" (ASSOCIATION..., 2009, p. 23) com o propósito de integrar a dimensão internacional, intercultural ou global em uma IES. Uma dessas atividades, e talvez uma das primeiras que as IESs realizam na busca da internacionalização, é a celebração de convênios bilaterais com universidades estrangeiras para a realização de intercâmbio de estudantes e professores. Entretanto, Miura (2006) adverte que o processo de internacionalização do ensino superior apresenta dificuldades inerentes que dificultam sua avaliação e gestão.

Segundo o Ministério do Desenvolvimento, Indústria e Comércio Exterior (BRASIL, 2009), o foco de estudo do processo de internacionalização está vinculado a questões de organização e estratégia. Para que as organizações tenham um ganho de vantagens comparativas em relação ao mercado internacional é necessário que busquem eficiência em seus processos de negócio para redução de custos.

Entre as organizações tem havido uma tendência por estruturar a gestão em torno de processos, ao invés da tradicional estrutura funcional. Essa gradativa mudança tem ocorrido pelos seguintes motivos: aumento na frequência da encomenda dos produtos/serviços ofertados, necessidade de rápida transferência de informação e tomada de decisão; necessidade de se adaptar a mudanças na demanda e aumento da concorrência internacional (SEETHAMRAJU; MARJANOVIC, 2009). Essas mesmas condições podem ser identificadas no contexto do ensino superior. Essa forma de gestão em torno de processos tem sido chamada de gerenciamento de processos de negócio ou Business Process Management e é geralmente identificada pela sigla BPM.

O BPM promove transparência no ambiente organizacional interno, enquanto mudanças constantes ocorrem no ambiente econômico e mercadológico externo. 0 BPM tem sido uma das formas de lidar com o desafio da melhoria no desempenho dos processos de negócio organizacionais e tem contribuído para o aumento da competitividade, na medida em que promove a oferta de valor ao cliente e a satisfação dos objetivos estratégicos da organização (TRKMAN, 2010).

Portanto, o presente estudo tem como propósito verificar a aplicabilidade do gerenciamento de processos de negócio (BPM) na gestão de um dos processos mais fundamentais no processo de internacionalização de IESs, o processo de realização de convênios bilaterais, neste caso, entre uma universidade pública brasileira e universidades estrangeiras.

Assim, o estudo pretende contribuir principalmente de duas formas: A primeira, através da verificação da viabilidade de aplicação do BPM em uma área ainda pouco explorada na literatura. É raro encontrar estudos de BPM que incluam IESs como foco principal. Uma exceção é o trabalho de Ahmad, Francis e Zairi (2007), onde são apresentados os fatores críticos de sucesso na reengenharia de processos de negócio (Business Process Reengeneering - BPR) no gerenciamento de processos de negócio. A segunda forma de contribuição encontra-se na proposta de uma alternativa para a avaliação e gestão do processo de internacionalização do ensino superior para seus gestores.

\section{Fundamentação teórica}

\subsection{Internacionalização do ensino superior}

0 processo de internacionalização do ensino superior não ocorre de maneira homogênea. Lima e Maranhão (2009) indicam que a atuação na internacionalização do ensino superior pode ser ativa ou passiva. A internacionalização ativa, encontrada predominantemente nos países desenvolvidos, é caracterizada pela existência de políticas de Estado e institucionais que promovem a atração de alunos e professores estrangeiros, bem como a oferta de serviços educacionais no exterior e até a construção de campi em outros países. Já a internacionalização passiva, predominante nos demais países, caracteriza-se pela falta de uma política estatal e institucional contínua e por uma postura reativa à internacionalização do ensino superior. Esses países assumem principalmente o papel de fornecedores de alunos internacionais para as IESs dos países desenvolvidos. Essa diferença pode ser verificada na Tabela 1.

A posição de fornecedor da América Latina e Caribe fica bastante nítida quando juntos atraíram apenas 1,9\% de todo o contingente de alunos em trânsito internacional em 2007. É nesse contexto que os acordos bilaterais internacionais não apenas se inserem, mas também se revestem de fundamental importância como instrumentos para a internacionalização do ensino superior.

\subsection{Acordos institucionais internacionais}

Segundo De Wit (2002 apud MIURA, 2006), tradicionalmente as instituições estabelecem suas ligações com parceiros internacionais via convênios institucionais bilaterais, carta de intenções ou memorando de entendimento (memoranda of understanding). Tais acordos institucionais têm caráter de cooperação educacional visando a mobilidade de estudantes e professores, programas conjuntos para obtenção de créditos (joint degree program), desenvolvimento de currículo, cooperação em pesquisa, desenvolvimento de projetos internacionais, entre 
Tabela 1. Percentual de estudantes de cada região de origem enviados para a América do Norte, Europa Ocidental e América Latina e Caribe em 2007.

\begin{tabular}{|c|c|c|c|c|c|}
\hline \multirow[b]{2}{*}{ Regiões de origem } & \multicolumn{5}{|c|}{ Regiões de destino } \\
\hline & $\begin{array}{c}\text { América do Norte } \\
\% \%\end{array}$ & $\begin{array}{c}\text { Europa Ocidental } \\
\% \%\end{array}$ & $\begin{array}{c}\text { América Latina e Caribe } \\
\qquad \%\end{array}$ & $\begin{array}{c}\text { Outros destinos } \\
\%\end{array}$ & $\begin{array}{c}\text { Total } \\
\%\end{array}$ \\
\hline Estados árabes & 15,4 & 56,9 & 0,1 & 27,6 & 100 \\
\hline Europa Central e Oriental & 12,3 & 55,4 & 0,0 & 32,3 & 100 \\
\hline Ásia Central & 4,9 & 12,5 & 0,0 & 82,6 & 100 \\
\hline Ásia Oriental e Pacífico & 33,0 & 22,9 & 0,2 & 43,9 & 100 \\
\hline América Latina e Caribe & 43,2 & 30,9 & 22,9 & 3,0 & 100 \\
\hline América do Norte & 39,1 & 40,5 & 1,7 & 18,7 & 100 \\
\hline Europa Ocidental & 14,4 & 77,2 & 0,2 & 8,2 & 100 \\
\hline Ásia Meridional e Ocidental & 45,7 & 26,1 & 0,0 & 28,2 & 100 \\
\hline África Sub-Saariana & 17,4 & 49,8 & 0,9 & 31,9 & 100 \\
\hline Mundo & 23,7 & 41,2 & 1,9 & 33,2 & 100 \\
\hline
\end{tabular}

Fonte: UNESCO (2009).

outros. Esses acordos podem ser realizados nos departamentos, escolas ou em nível institucional (universidade), entretanto o autor afirma que a despeito da existência de acordos bastante concretos, muitos não passam da expressão de intenções.

Convênios ou acordos podem desenvolver-se em formas de parcerias internacionais mais robustas e complexas. Em anos recentes, nota-se o crescimento das associações, consórcios e redes de trabalho multilaterais (não somente bilaterais), refletindo o caráter de complementaridade de recursos no ensino superior. A respeito de consórcios, Neave (1992) desenvolve uma tipologia de cooperação interinstitucional elaborando um continuum de cinco estágios: ligações bilaterais monodisciplinares, estabelecimento de parcerias, redes de parcerias, redes de trabalho multidisciplinares e consórcios.

De Wit (2002 apud MIURA, 2006) propõe a distinção de três tipos de organizações multilaterais internacionais em educação superior: associações acadêmicas, consórcios acadêmicos e redes de trabalho (networks) institucionais.

Associações acadêmicas são organizações de acadêmicos ou administradores e/ou suas unidades organizacionais (departamentos, centros, escolas e instituições) unidas por um propósito comum e relacionadas ao desenvolvimento profissional (troca de informações, treinamento, direito etc). Recentemente,0 número de associações institucionais (multipropósitos) e associações individuais administrativas têm aumentado. Exemplos dessas associações institucionais e individuais são respectivamente: International Association of Universities (IAU) e Associação Internacional de Presidentes de Universidades.

Consórcio acadêmico refere-se a um grupo de unidades acadêmicas (departamentos, centros, escolas e instituições) que se unem com o propósito de realização de um contrato baseado na união de diferentes áreas de conhecimento especializado. Um exemplo desse tipo de consórcio é o Programa de Estudos Conjuntos do sistema Erasmus (na área de ensino) caracterizado por acordos focados em intercâmbio de estudantes, professores e desenvolvimento do currículo. Outra tendência comum nessa área são os consórcios acadêmicos internacionais, especialmente em razão do desenvolvimento de pesquisa conjunta. Esses consórcios surgem para atender às demandas de diferentes instituições parceiras que necessitam complementar-se mutuamente em termos de habilidades, experiências e facilidades oferecidas pelas instituições envolvidas. Esses arranjos dependem de recursos financeiros externos para ter sucesso. Exemplos deste tipo de apoio externo são fornecidos pelo Joint Iniciative Program (JIP) e o Programa de Bolsas Ryoichi Sasakawa Young Leader Fellowship Fund (SYLFF).

As redes de trabalho (networks) institucionais são uma tendência nos acordos multilaterais, porém menos focadas em objetivos do que as associações e consórcios. Trata-se de um grupo de unidades acadêmicas (departamentos, centros, escolas e instituições) unidas por múltiplos propósitos, ou seja, objetivos gerais (acadêmicos e/ou administrativos). São exemplos de redes de trabalho: Coimbra Group, Midwest Universities Consortium for International Activities Inc. (MUCLA), Associación de Universidades Grupo Montevideo (AUGM).

As modalidades de parcerias entre IES estrangeiras são bastante variadas em seus propósitos e complexidade. A celebração de convênios institucionais internacionais bilaterais, uma dessas modalidades e o foco deste estudo, é essencial para que se desenvolvam outras formas de parcerias mais complexas. Daí a necessidade de se considerar abordagens específicas de gestão desse processo. Dentre as abordagens possiveis, 
propõe-se a seguir o gerenciamento de processos de negócio ou Business Process Management (BPM).

\subsection{Business Process Management (BPM)}

BPM significa alcançar os objetivos organizacionais através da melhoria, gestão e controle de processos essenciais (JESTON; NELIS, 2006). De acordo com Palmberg (2010), os motivos que levam uma organização a buscar o BPM são particulares a cada organização. Entretanto, é possível identificar os motivos mais comuns (JESTON; NELIS, 2006):

- A organização apresenta crescimento acentuado levando a dificuldades em atingir seus objetivos e perda de controle e agilidade para aproveitar oportunidades;

- Há dificuldades no gerenciamento, com informações imprecisas e/ou conflitantes e necessidade de cortar custos e aumentar produtividade;

- Ocorre alta rotatividade, falta de preparo e insatisfação dos colaboradores;

- Há aumento no número de clientes, fornecedores ou parceiros e elevam-se as exigências em atendê-los através de um relacionamento de proximidade;

- Os produtos e serviços oferecidos são complexos e há duplicação de tarefas;

- Não há visão dos processos ponta a ponta, gerando lacunas e falta de padronização e clareza quanto a responsabilidades; e

- Ocorrem introdução ou eliminação de sistemas de informação.

No caso deste estudo, os fatores que motivam a consideração do BPM são, prioritariamente, a percepção da complexidade do processo de internacionalização e a busca de uma visão ponta a ponta desse processo, começando pela realização de convênios bilaterais.

Como um processo envolve o trabalho até a entrega de valor ao cliente, os processos transpõem as fronteiras funcionais/departamentais tradicionais da organização e podem ser classificados entre processos primários, de suporte ou de gerenciamento. Os processos primários são compostos pelas atividades essenciais que cumprem a missão organizacional, formando a cadeia de valor interfuncional ponta a ponta de entrega de valor ao cliente. Os processos de suporte prestam apoio aos processos primários, não geram valor direto ao cliente e geralmente estão ligados ao gerenciamento de recursos e infraestrutura. Os processos de gerenciamento são aqueles utilizados para medir, monitorar e controlar as atividades organizacionais, pois garantem a eficiência e a eficácia no alcance dos objetivos e metas (ASSOCIATION..., 2009).
Para melhor identificar e estabelecer prioridades entre processos primários, Oliveira (2009) sugere que os processos primários sejam classificados ainda entre processos-chave e processos críticos. Os processos-chave são os que têm custo elevado para a organização e alto impacto para o cliente. Já os processos críticos são os processos-chave que se relacionam diretamente com a estratégia organizacional.

Os processos são compostos por atividades e estas podem ser separadas em três categorias (ASSOCIATION..., 2009):

- Atividades de valor agregado - Somam ao resultado do processo;

- Atividades de Handoff - Transferem o controle do processo para outra função ou departamento organizacional; e

- Atividades de controles - Garantem que os processos ocorram dentro dos padrões desejados e predeterminados, são atividades que checam o desenvolvimento do processo.

As tarefas que compõem um processo também podem ser classificadas quanto aos seus resultados. Assim, há tarefas de desenho dos processos, tarefas de gerenciamento do cotidiano dos processos e tarefas de melhoria e aprendizado com os processos (PAIM; CAULLIRAUX; CARDOSO, 2008).

Independente das tarefas envolvidas, o BPM se desenvolve como um ciclo de vida contínuo em seis atividades integradas (ASSOCIATION..., 2009):

- Planejamento e estratégia - Direcionam todo o BPM, fornecem a orientação, as metas e a concepção de agregação de valor para o cliente, proporcionam uma visão holística da organização, alinham o BPM à estratégia da organização e estabelecem as expectativas, os papéis e responsabilidades;

- Modelagem - Representa graficamente o processo com a avaliação de fatores do ambiente que afetam o desempenho do processo;

- Análise - À luz do plano estratégico, dos objetivos, metas e outras informações disponíveis na organização, os processos são analisados através de metodologias diversas;

- Desenho - É a criação de novos processos ou a modificação dos processos, considerando a análise feita;

- Monitoramento e medição - 0 acompanhamento contínuo do desempenho do processo para obter informações que indiquem ajustes, melhoria, redesenho ou reengenharia necessários; e

- Transformação - Ao final do ciclo, é possível propor ações de melhoria contínua e otimização dos processos. 
A Association of Business Process Management Professionals (2009) define a modelagem de processos como uma representação simplificada de um conjunto de atividades (processo) ponta a ponta. 0 modelo pode conter um ou mais diagramas e incluir informações sobre os objetos dos processos, sobre as inter-relações entre esses objetos, sobre as relações dos objetos com o ambiente, sobre o comportamento e desempenho desses processos. Portanto, para se modelar um processo é necessário detalhá-lo em suas atividades constitutivas.

A modelagem também é importante para que um projeto de implantação de BPM seja validado. É através da modelagem que se viabilizam a consolidação do conhecimento, a identificação e formulação de mudanças. Por isso, deve-se escolher uma metodologia e técnicas consagradas e adequadas para o contexto. A metodologia define como será feita a análise de como está o processo (as is), como deveria ser (should be) e qual a melhor opção de mudanças a serem implementadas, dadas as condições reais da organização (to be). (OLIVEIRA; ALMEIDA NETO, 2009).

A abordagem para modelar pode ser de cima para baixo (top-down), de baixo para cima (bottom-up) ou do meio para cima ou para baixo (middle-out). A escolha da abordagem depende do objetivo e da abrangência da modelagem. A abordagem de baixo para cima pode ser indicada quando o foco é melhorar os processos de um departamento ou quando não há qualquer documentação dos processos organizacionais e é necessário descobrir o que está acontecendo. Se a intenção é melhorar os processos interfuncionais de ponta a ponta, abrangendo toda a organização e promovendo melhor alinhamento entre processos e estratégia, a abordagem indicada é a de cima para baixo (ASSOCIATION..., 2009). Para este projeto, tomando-se como foco o International Office da Escola de Negócios de um dos campi da IES, foi usada a abordagem top-down.

Independentemente da abordagem, Jeston e Nelis (2006) recomendam que haja uma busca constante por entregar valor perceptível à organização. Desde o início o BPM deve oferecer benefícios, ganhos e pequenas vitórias à organização. Ou seja, a implantação do BPM obterá melhores resultados se for realizada aos poucos, a partir de pequenas e diversas intervenções críticas e essenciais, ao invés de ser realizada com apenas uma ou poucas intervenções de amplo alcance organizacional. De acordo com Jeston e Nelis (2006), grandes intervenções demandam muito tempo para oferecerem resultados perceptíveis, o que acaba muitas vezes pondo em descrédito o BPM. Considerando essa recomendação, este estudo propõe a aplicação de BPM para apenas um processo estrategicamente essencial no processo de internacionalização de uma IES, o processo de realização de convênios bilaterais.

Há diversas formas de notação que podem ser usadas na modelagem de processos, tais como fluxogramas, raias, Event Process Chain (EPC), cadeia de valor, Business Process Modeling Notation (BPMN), entre outras (ASSOCIATION..., 2009). Neste trabalho foi utilizada a notação BPMN. De acordo com o Object Management Group (OBJECT..., 2009), o BPMN é uma notação padronizada, utilizada no desenho e modelagem de processos que procura também facilitar a implantação da gestão desses processos. Muito embora seja um padrão de notação relativamente novo (lançado oficialmente em 2006, pelo OMG e BPMl - Business Process Management Initiative), nenhuma outra notação tornou-se tão vastamente utilizada em tão pouco tempo e com tão amplo suporte por parte de organizações comerciais e educacionais, influenciando inclusive outras formas de notação previamente existentes (RECKER, 2010). Dentre as vantagens do BPMN indicadas por Ko, Lee e Lee (2009) destacam-se neste estudo a melhora no diálogo entre as áreas de gestão e tecnologia da informação e a maior facilidade de tradução para os códigos de execução de processos. Ambos essenciais quando a melhoria de processos é realizada através de automatização. Maiores detalhes sobre o BPMN podem ser obtidos no site da OMG (www.omg.org).

Uma vez que os processos são modelados, torna-se mais claro para os gestores como e onde otimizá-los. Gonzalez et al. (2010) afirmam que existe grande crescimento nas pesquisas relacionadas à medição de processos de negócio com o objetivo de melhorar toda a organização. Kohlbacher (2010) destaca como principais efeitos da orientação por processo a velocidade nas melhorias, o aumento da satisfação do cliente, a melhoria na qualidade dos produtos/serviços, a redução de custos e a melhoria do desempenho financeiro. A gestão por processos provê 0 desenvolvimento e a melhoria contínua de estratégias e faz com que as organizações concentrem-se na geração de valor e melhoraria de seu desempenho (McCORMACK et al., 2009).

Essa melhoria contínua é promovida também pela adoção de indicadores que permitem o monitoramento e avaliação de um processo. Gonzales et al. (2010) afirmam que a medição dos processos é importante para entender atividades e riscos envolvidos nos processos, controlar as atividades, gerenciar os riscos, prever o tempo de conclusão do processo e gerenciar de forma pró-ativa para evitar crises no ambiente organizacional. Por isso, todos os processos devem ter uma medição associada com suas saídas, tendo como base as seguintes dimensões fundamentais (ASSOCIATION..., 2009): 
- Tempo: É a métrica de duração do processo;

- Custo: É a métrica do valor monetário associado a um processo, que pode considerar tanto o custo dos recursos necessários quanto o custo de oportunidade;

- Capacidade: É a métrica que considera o montante ou volume de uma saída, produto ou serviço variável associado a um processo; e

- Qualidade: É a métrica que considera a satisfação do cliente, a taxa de variação entre o resultado esperado e o resultado realizado e a taxa de erros ou defeitos no processo.

Segundo Palmberg (2010), os resultados esperados com a aplicação do BPM são o fortalecimento da habilidade de mudar e melhorar da organização e a inclusão da estrutura de processos dentro da estrutura tradicionalmente funcional. Paim, Caulliraux e Cardoso (2008) destacam que na gestão funcional os processos são geridos isoladamente, a organização tem características de silos com baixa capacidade de coordenação e baixa orientação para o mercado. $\mathrm{Na}$ gestão por processos, há alterações na estrutura organizacional e em outros elementos integrantes do projeto organizacional. Os processos, e não mais as funções, passam a ser priorizados como eixo gerencial de maior importância, orientando, consequentemente, as decisões organizacionais. Palmberg (2010) reconhece que em função do cruzamento de responsabilidades e autoridades de uma estrutura matricial, um dos possiveis efeitos colaterais é o aumento do estresse entre os colaboradores por causa do aumento das responsabilidades individuais. Porém, o mesmo autor afirma que, apesar disso, as pessoas afetadas tendem a perceber a aplicação do BPM como algo positivo.

Outro benefício que torna o BPM especialmente recomendável para a gestão dos processos de uma IES é a manutenção da gestão do capital intelectual. De acordo com Kujansivu e Lönngvist (2008), o BPM viabiliza a identificação do capital intelectual de uma organização a partir da análise de seus processos e contribui para o desenvolvimento de capital intelectual no nível operacional.

\section{Método}

0 método utilizado neste estudo é de natureza qualitativa, uma vez que o processo de realização de convênios foi estudado a partir da perspectiva dos envolvidos, sem a intenção de generalizar os resultados, mas de aplicá-los, o que o caracteriza também como uma pesquisa aplicada e de campo.

A pesquisa de campo justifica-se na medida em que os pesquisadores obtiveram as informações necessárias em contato direto com os responsáveis pelo processo em seu local de trabalho, o International Office da Escola de Negócios de um dos campi de uma IES pública brasileira, localizado no interior do estado de São Paulo. Já o caráter aplicado deste estudo revela-se na intenção de propor e implantar melhorias no processo estudado.

Quanto aos fins, trata-se de um estudo tanto descritivo quanto intervencionista. Num primeiro momento, o objetivo é descrever como o processo se desenvolve. A partir dessa descrição, um primeiro modelo foi elaborado. Porém, também foi conduzida a análise do processo, com o intuito de identificar possibilidades de melhoria. Seguiu-se, então, uma segunda modelagem que, por propor mudanças e implantá-las parcialmente, dá ao estudo também caráter intervencionista.

Os meios utilizados para a coleta de dados foram, em primeiro lugar, as fontes bibliográficas, a fim de buscar respaldo teórico para o estudo. Também foram usadas fontes documentais de onde se obtiveram informações como missão, objetivos, dados históricos do International Office em estudo, além das regras e normas que interferem na execução do processo.

Entretanto, a maior parte dos dados relativos ao processo foi obtida através de entrevistas semiestruturadas, realizadas diretamente com os envolvidos e responsáveis pelo processo. Foram realizadas três entrevistas com o responsável pelo International Office e duas com o diretor da Comissão de Relações Internacionais da Escola de Negócios. As entrevistas, com duração média de 55 minutos, foram realizadas entre os meses de abril e junho de 2010. Elas foram gravadas, transcritas e analisadas para a identificação de atividades, pontos críticos e possibilidades de melhorias.

Para a elaboração e análise do modelo adotou-se o método proposto por Oliveira e Almeida Neto (2009), adaptado para a realidade deste estudo. 0 método é composto de quatro fases. A primeira, de preparação, incluiu a busca de material bibliográfico e documental, bem como os primeiros contatos com o International Office e seus responsáveis. A segunda, de análise do processo, foi realizada mediante as entrevistas e a modelagem do processo. A terceira fase, de identificação das melhorias do processo, foi proposta pelos pesquisadores através da elaboração de um novo modelo de processo. 0 novo modelo foi apresentado ao International Office, juntamente com a proposta de indicadores de desempenho para avaliação, monitoramento e gestão do processo. Já a quarta e última fase foi a implantação do processo modificado, realizada à medida em que a instituição adotou as mudanças sugeridas. 


\section{Apresentação e análise de dados}

Antes de dar início às atividades de modelagem, análise e desenho do processo, é essencial conhecer a organização, seu contexto, sua missão e objetivos estratégicos. Trata-se da fase de preparo.

\subsection{Preparação para análise do processo}

0 International Office em foco neste estudo está inserido dentro da estrutura organizacional extensa e complexa, típica de uma grande IES pública brasileira. Localizada no estado de São Paulo, a IES possui diversos campi espalhados pelo estado. No campus da capital encontra-se o International Office Central, que averigua e autoriza ou não todos os convênios realizados nos diversos International Offices dos demais campi, garantindo a padronização jurídica e orçamentária dos convênios.

0 International Office da Escola de Negócios está subordinado à Comissão de Relações Internacionais. Essa comissão é composta por professores que representam os cursos da escola, um professor presidente da comissão e é assessorada por uma secretária e um estagiário. As pessoas diretamente envolvidas no cotidiano do International Office da Escola de Negócios são: o professor presidente da Comissão de Relações Internacionais, que também atua como presidente do International Office, a secretária e o estagiário. Quem gerencia as questões operacionais do International Office é a secretária.
O International Office e a Comissão de Relações Internacionais não estão formalmente designados no organograma da Escola de Negócios. 0 International Office está inserido na Seção Técnica de Convênios e Projetos, que tem outras atribuições além das atividades ligadas ao International Office. A Comissão de Relações Internacionais é considerada como parte da direção da Escola de Negócios (Figura 1).

Em termos de subordinação, todos os convênios propostos pelo International Office precisam ser submetidos à aprovação em dois níveis. No nível da Escola de Negócios e no nível da IES, por meio do International Office Central.

0 objetivo estratégico geral do International Office da Escola de Negócios pode ser resumido em: integrar a dimensão internacional em ensino, pesquisa e extensão na Escola de Negócios, promovendo a sustentabilidade do processo de internacionalização da Escola de Negócios e da IES.

0 International Office busca a realização desse objetivo principal através dos seguintes objetivos específicos:

- Proporcionar aos estudantes visão global e competência intercultural;

- Incentivar e coordenar programas internacionais para alunos e professores da Escola de Negócios;

- Possibilitar parcerias e pesquisas conjuntas entre a Escola de Negócios e outras Escolas de Negócios estrangeiras (convênios); e

- Divulgar o conhecimento científico produzido na Escola de Negócios.

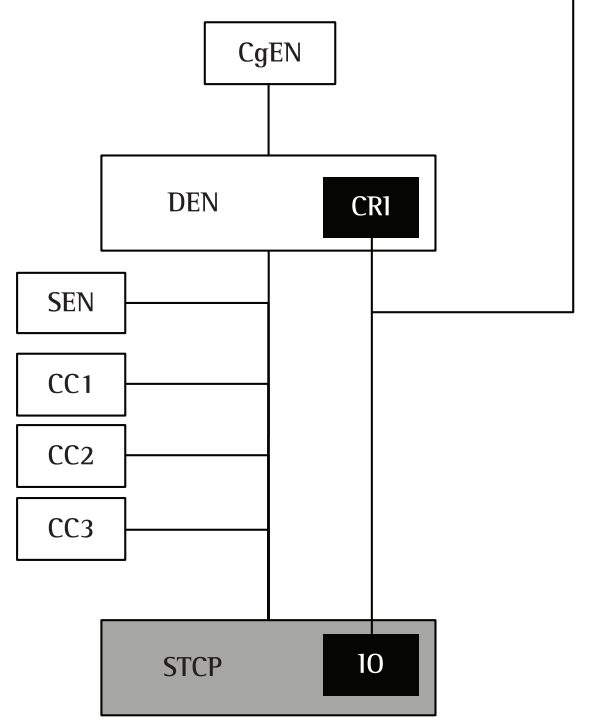
Legenda:
$10 C$ - International office central
CgEN - Congregação da escola de negócios
DEN - Direção da escola de negócios
CRI - Comissão de Relações Internacionais
SEN - Secretaria da escola de negócios
CC1 - Comissão do curso 1
CC2 - Comissão do curso 2
CC3 - Comissão do curso 3
CRI - Comissão de relações internacionais
STCP - Seção técnica de convênios e projetos
10 - International office

Figura 1. Inserção do International Office na estrutura organizacional da IES. 
O objetivo estratégico geral e os objetivos específicos podem perfeitamente ser compreendidos, respectivamente, como macroprocesso e processos do International Office. Cada um desses processos é composto por subprocessos, atividades e tarefas. Por exemplo, a criação de competência intercultural é atingida através da inclusão de alunos estrangeiros nos cursos da Escola de Negócios, bem como no envio de alunos da Escola de Negócios para o estrangeiro.

Há um processo essencial sem o qual a viabilização de todos os demais processos e objetivos estratégicos fica impedida ou prejudicada: o processo de realização de convênios. Quaisquer melhorias propostas nesse processo têm o potencial de proporcionar diversos impactos positivos em todo o International Office, gerando agregação de valor imediatamente. Trata-se, portanto, de um processo primário e crítico.

0 processo de realização de convênios é composto pelas seguintes fases (Figura 2):

- Abordagem - Primeiros contatos entre as IESs e obtenção das informações para redigir o convênio;

- Elaboração e negociação do convênio - É feita a redação do convênio cujos termos são esclarecidos e negociados com a IES estrangeira;

- Aprovação do convênio - 0 convênio é encaminhado para aprovação nas instâncias da IES;

- Assinatura do convênio - 0 convênio é impresso e encaminhado para ser assinado pela direção da Escola de Negócios e pelo responsável na IES estrangeira; e

- Publicação e monitoramento do convênio - 0 convênio é publicado no diário oficial do estado e a partir da data de publicação passa a vigorar pelo prazo máximo de cinco anos, ao final do qual o International Office avalia a renovação do convênio.
A partir dessa contextualização, o processo de convênio foi então analisado e descrito na forma de um modelo.

\subsection{Análise do processo (modelo as is)}

Para facilitar a compreensão do modelo existente (as is), o mesmo será apresentado detalhando cada uma de suas fases (Figura 3).

\subsubsection{Abordagem}

Esta etapa do processo pode ser iniciada de três formas: por indicação de uma universidade estrangeira por um professor, por indicação de uma universidade estrangeira por um aluno ou pela prospecção ativa do International Office de uma universidade estrangeira.

A partir da indicação de uma IES estrangeira, o International Office passa a buscar informações preliminares, que podem incluir a checagem da existência da IES, a verificação da existência de um International Office na IES estrangeira, os cursos oferecidos, as áreas de atuação e a existência de convênios com outras universidades. Essas informações são registradas e enviadas ao presidente da Comissão de Relações Internacionais, que avalia o interesse da Escola de Negócios em desenvolver um convênio com a universidade em questão. Caso o presidente da Comissão de Relações Internacionais não a aprove o processo se encerra. Caso a IES estrangeira seja aprovada, o International Office prossegue com os contatos iniciais.

0 International Office envia um e-mail padrão para o International Office da IES estrangeira, apresentando a Escola de Negócios e indicando interesse em celebrar um convênio. Nesse mesmo e-mail também são solicitadas as

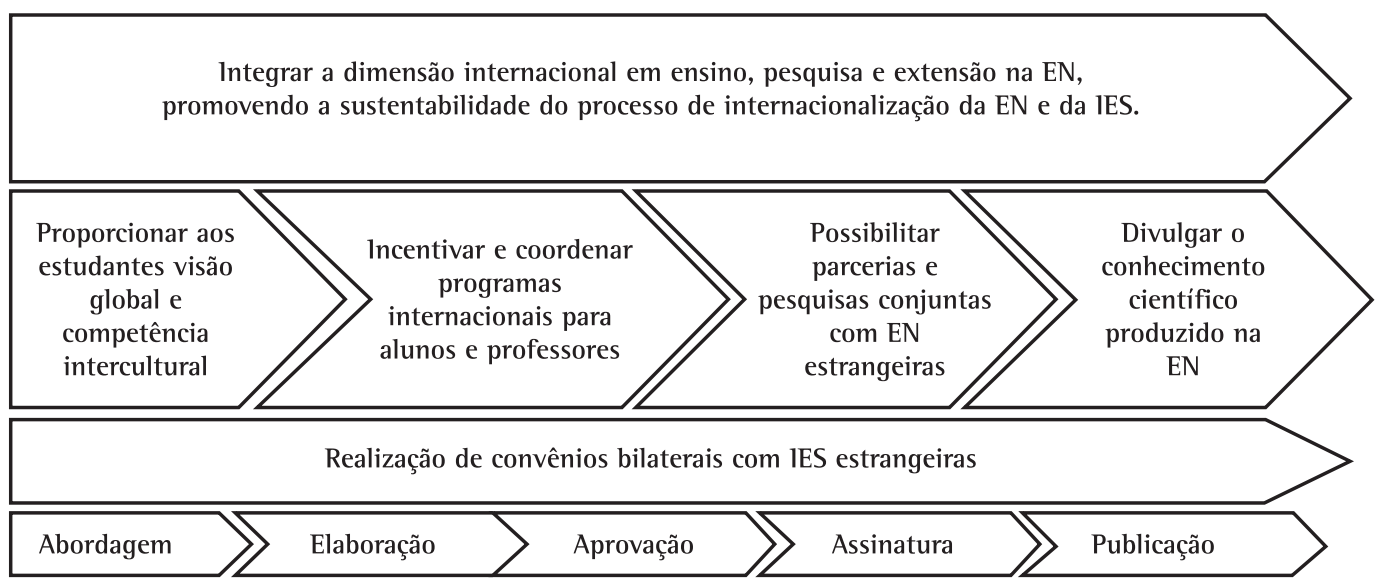

Figura 2. Objetivos estratégicos do International Office e o processo de realização de convênios. 


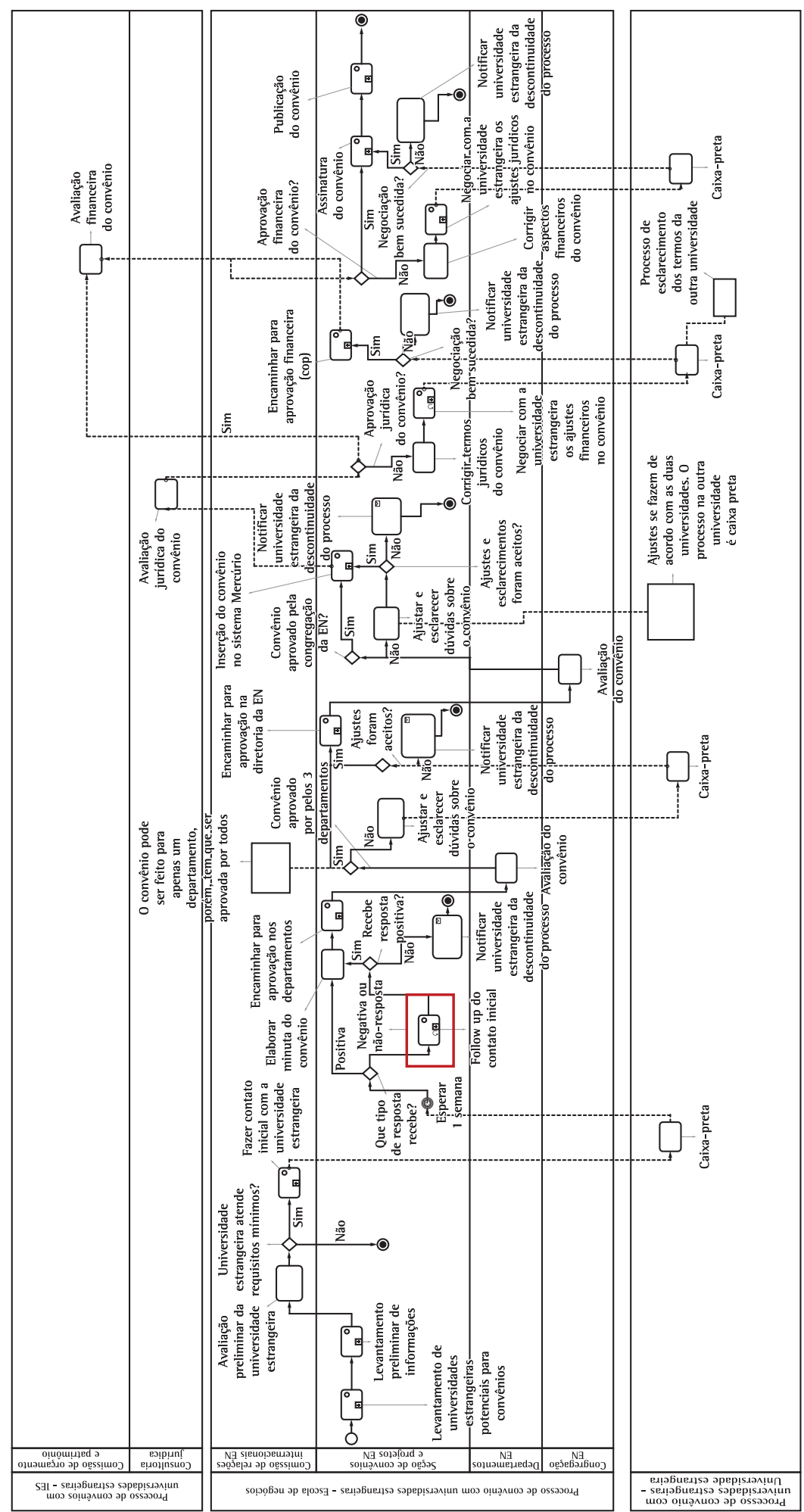

Figura 3. Modelo as is para a celebração de convênios bilaterais internacionais com a atividade de followup em destaque. 
informações necessárias para a elaboração do convênio. Anexados a este primeiro e-mail seguem o Student Guide, o modelo de convênio e o cronograma de aulas.

0 International Office aguarda por uma resposta da universidade estrangeira durante uma semana. Respostas positivas ou negativas fazem o processo avançar para a etapa de elaboração do convênio. No caso de uma não resposta, os contatos são checados e o e-mail é reenviado. Esse procedimento é repetido por até três vezes. Se após a terceira tentativa a universidade estrangeira não responder, o International Office avalia o nível de interesse da Escola de Negócios em fazer o convênio. Caso seja um convênio importante para a escola, o International Office faz uma última tentativa enviando todo o material por correio. Se após quatro semanas depois do envio não houver resposta, o processo é encerrado através de um comunicado formal enviado ao International Office da IES estrangeira.

\subsubsection{Elaboração do convênio}

A etapa de elaboração do convênio inicia-se a partir do momento em que o International Office recebe uma resposta da IES estrangeira. Se há uma resposta positiva e se a IES estrangeira envia as informações necessárias, o International Office elabora então a minuta do convênio.

No caso de uma resposta negativa, o International Office verifica os motivos da negação. Se os motivos podem ser eliminados através de ajustes nos termos e condições do convênio, o International Office inicia as negociações com a universidade estrangeira. 0 propósito é obter uma resposta positiva e, ao mesmo tempo, conseguir um convênio que esteja dentro dos padrões acadêmicos, jurídicos e orçamentários da escola. Caso a negociação não seja bem-sucedida, o processo é descontinuado através de um comunicado formal à universidade estrangeira. Se a negociação é bem-sucedida, a minuta do convênio é elaborada.

\subsubsection{Aprovação do convênio}

O convênio deve ser aprovado em quatro instâncias. Duas delas ocorrem no nível da própria Escola de Negócios, são elas: Diretoria/ Congregação e Departamentos/Cursos. E outras duas, em esfera institucional: Assessoria Jurídica e Comissão de Orçamento e Patrimônio, ambas ligadas ao International Office Central. Na instância departamental, o convênio é enviado aos chefes de departamento da Escola de Negócios, que deverão individualmente em seus departamentos decidir sobre a aprovação do convênio. Caso haja alguma dúvida ou inadequação às normas, o convênio volta para o International Office para ser ajustado. Porém, trata-se de um fato raro, pois já há conhecimento dos requisitos necessários para aprovação do convênio por parte do International Office. Quando isso ocorre negociam-se os ajustes com a IES estrangeira. Sendo bem-sucedida essa negociação, o convênio é reenviado ao chefe de departamento que solicitou as mudanças. Na instância da diretoria, ocorre procedimento semelhante. Porém, decidem sobre a aprovação o diretor juntamente com a Congregação da Escola de Negócios.

A partir do momento em que o convênio é aprovado no nível da Escola de Negócios, pode ser enviado para aprovação institucional no International Office Central. A primeira instância é a Assessoria Jurídica. Uma vez que a minuta do convênio já é padronizada de acordo com os requisitos jurídicos, a princípio, dificuldades de aprovação não deveriam ser muito comuns. Entretanto, caso isso ocorra, o convênio volta para o International Office, que entra em contato com a Assessoria Jurídica para identificação do problema e negocia os ajustes necessários junto a IES estrangeira. Sendo essa tarefa bem-sucedida, o convênio é reenviado à Assessoria Jurídica para nova apreciação.

A última instância pela qual o convênio passa é pela Comissão de Orçamento e Patrimônio. 0 que ocorre na prática é aprovação de 100\% dos convênios, pois nenhum deles acarreta novos custos financeiros à IES, além dos já previstos para a manutenção do International Office e suas atividades.

\subsubsection{Assinatura do convênio}

Concluída a etapa de aprovação, o convênio é assinado pelo diretor da Escola de Negócios. Comunica-se à IES estrangeira, através de e-mail, sobre a aprovação e assinatura do convênio. 0 convênio assinado no Brasil (4 vias - 2 em português e 2 em língua estrangeira) é enviado por correio à IES estrangeira, para que o responsável na instituição o assine e o devolva (2 vias - 1 em cada língua) também assinado. 0 convênio quando recebido pelo International Office é arquivado.

\subsubsection{Publicação e monitoramento do convênio}

Concluída a fase anterior, o convênio é publicado no diário oficial do estado, passando a ter valor legal a partir da data de publicação. 0 convênio, então, tem validade por até cinco anos. Ao final deste prazo, o International Office avalia a renovação do convênio. 


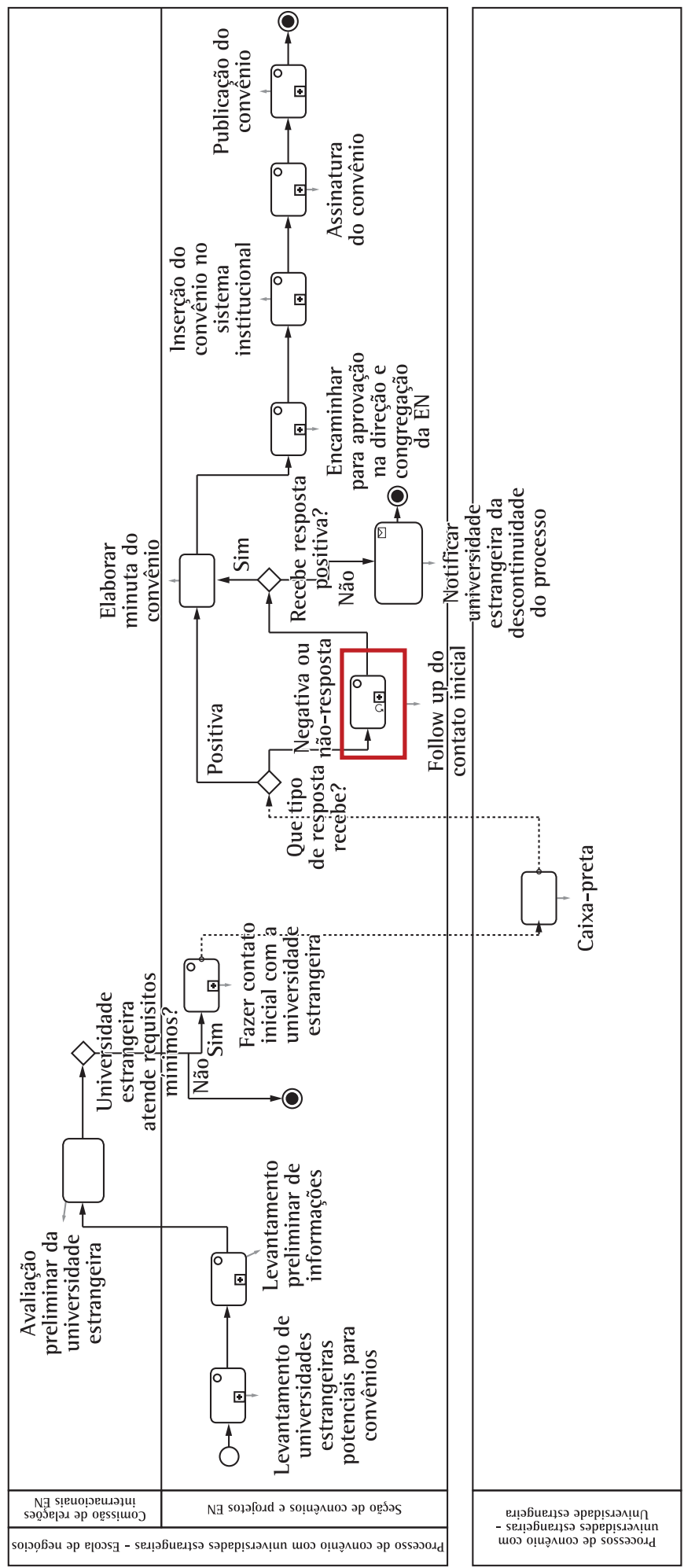

Figura 4. Modelo to be para celebração de convênios bilaterais internacionais com a atividade de followup em destaque. 


\subsection{Proposta de melhorias no processo (modelo to be)}

Uma vez que o processo foi mapeado, refletindo a forma de funcionamento vigente, torna-se mais fácil a percepção de problemas e pontos críticos que interferem na eficiência do processo, na geração de valor e no alcance dos objetivos estratégicos. De acordo com Paim et al. (2009), é central documentar as melhorias propostas. Uma das formas de documentar essas oportunidades de melhoria é através do modelo to be. Por isso, o passo seguinte e lógico é repensar o processo, propondo melhorias e soluções.

0 objetivo central do modelo to be foi aumentar a produtividade, reduzir atividades de hand-off e garantir a qualidade dos convênios realizados pelo International Office. 0 alcance desse objetivo central depende essencialmente de dois objetivos específicos utilizados para o novo modelo:

- Reduzir o gasto de tempo e, consequentemente, custos. Em função de exigências exclusivamente burocráticas; e

- Inserir mecanismos que gerem aprendizado e melhoria contínua, tanto na capacidade quanto na qualidade do processo.

Com esses objetivos em mente, foram propostas algumas modificações que resultaram num modelo mais simples (Figura 4).

Com o propósito de reduzir o tempo gasto com o processo, foram feitas as seguintes alterações no modelo:

- Eliminação da aprovação pelos departamentos da Escola de Negócios. Cada departamento possui datas específicas para deliberar e tomar decisões, que nem sempre coincidem com as urgências do International Office. Portanto, o tempo necessário para que haja aprovação de todos os departamentos acarreta necessariamente em perda de prazos e oportunidades de convênios. Além disso, os departamentos já são devidamente representados tanto na Comissão de Relações Internacionais quanto na Congregação da Escola de Negócios;

- Automatização da aprovação por parte da Assessoria Jurídica da IES. É importante destacar que o International Office utiliza uma minuta de convênio padrão, previamente aprovada pela Assessoria Jurídica. Entretanto, quando um convênio não é aprovado, é devolvido ao International Office para que seja refeito. 0 International Office, nesse caso, deve buscar a Assessoria Jurídica para identificar onde está o problema no convênio e corrigi-lo. Atualmente, a aprovação do convênio por parte da Assessoria Jurídica ocorre mediante o preenchimento de um formulário eletrônico e envio de cópia escaneada do convênio através do sistema institucional. A proposta é que o próprio sistema detecte violações aos pré-requisitos jurídicos de aprovação. Para tanto, seria necessário estipular os parâmetros mínimos e máximos aceitáveis

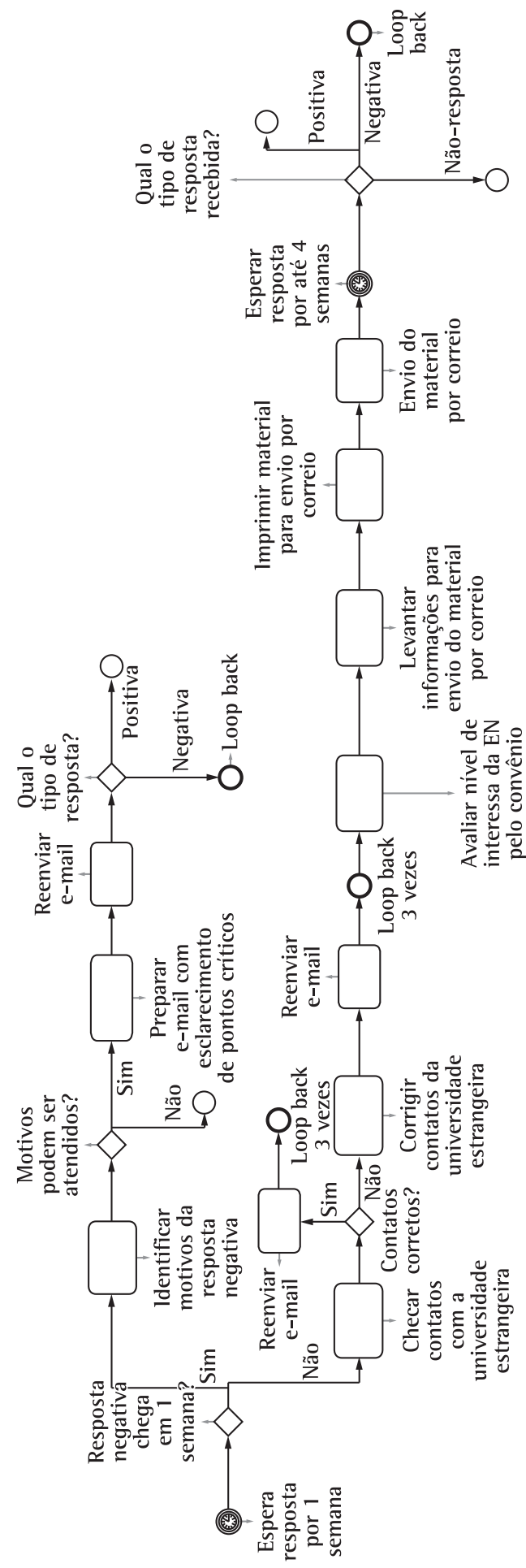

Figura 5. Detalhamento da atividade de followup. 
nos aspectos jurídicos essenciais e condicionar o preenchimento dos campos no formulário eletrônico ao atendimento desses parâmetros. Assim, o próprio sistema poderia impedir a inserção de convênios inapropriados e apontar instantaneamente ao International Office as correções a serem feitas. As exceções deveriam ser tratadas como situações especiais. Somente nesses casos o International Office buscaria esclarecimentos junto à Assessoria Jurídica para fazer os devidos ajustes; e

- Eliminação da aprovação pela Comissão de Orçamento e Patrimônio. 0 convênio padrão é muito claro no sentido de que o intercambista tem compromissos financeiros apenas com a IES de origem. Como se trata de uma IES pública e gratuita, o intercambista brasileiro tem a gratuidade dos estudos garantida no exterior. Além disso, as cláusulas do convênio padrão já foram previamente aprovadas pela própria Comissão de Orçamento e Patrimônio. Quaisquer aspectos que envolvam acordos financeiros, o convênio deixa claramente estipulado que deverão ser negociados separadamente.
Através das Figuras 3 e 4 pode ser feita uma comparação em termos de redução de complexidade entre o modelo as is e o modelo to be.

Outro aspecto do modelo as is que foi identificado como passivel de melhorias é o de followup do contato com a IES estrangeira. Envolve as fases de abordagem e elaboração do convênio. Uma vez feito o primeiro contato por e-mail com a IES estrangeira, as possibilidades de retorno são as seguintes: 1) não responder; 2) demorar a responder; 3) responder de forma incompleta; 4) responder com ressalvas à proposta de convênio enviada; 5) responder positivamente à proposta de convênio e de forma completa. Em função de todas essas possibilidades, o modelo perde em simplicidade. Na Figura 5, é possível ter uma noção da complexidade existente dentro da atividade de folowup, cuja localização nos processos as is e to be foi destacada nas Figuras 3 e 4.

Muito embora haja a percepção de que o processo pode ser simplificado, não foi feita qualquer proposta de melhoria, pois antes é preciso inserir mecanismos que permitam um diagnóstico mais preciso. Daí

Quadro 1. Indicadores de desempenho para o processo de realização de convênios bilaterais entre a Escola de Negócios e IES estrangeiras.

\begin{tabular}{|c|c|c|c|c|c|}
\hline Nome (sigla) & Fase & Objetivo & Fórmula & Entrada & Saída \\
\hline $\begin{array}{l}\text { Origem da } \\
\text { indicação de } \\
\text { convênio (OC) }\end{array}$ & Abord. & $\begin{array}{l}\text { 1dentificar as fontes } \\
\text { mais frequentes } \\
\text { de indicação para } \\
\text { contatos iniciais. }\end{array}$ & $O C=\left(\frac{\sum \text { Fonte }_{i}}{\sum \text { Indicações }}\right) \times 100$ & $\begin{array}{l}\text { Registro da fonte de } \\
\text { indicação para o primeiro } \\
\text { contato. }\end{array}$ & $\begin{array}{l}\text { Gráfico com } \\
\text { a participação } \\
\text { percentual das fontes } \\
\text { de indicação de } \\
\text { contatos iniciais. }\end{array}$ \\
\hline $\begin{array}{l}\text { Contatos } \\
\text { recorrentes } \\
\text { (CR) }\end{array}$ & Abord. & $\begin{array}{l}\text { ldentificar os } \\
\text { motivos mais } \\
\text { frequentes de } \\
\text { reenvio de e-mails. }\end{array}$ & $C R=\left(\frac{\sum \text { Motivo }_{i}}{\sum \text { Reenvios }}\right) \times 100$ & $\begin{array}{l}\mathrm{N}^{0} \text { de e-mails reenviados } \\
\text { classificados por motivo } \\
\text { de reenvio; } \\
\mathrm{N}^{0} \text { de e-mails reenviados } \\
\text { durante abordagem } \\
\text { e followup de um } \\
\text { convênio. }\end{array}$ & $\begin{array}{l}\text { Gráfico com o } \\
\text { percentual dos } \\
\text { motivos de reenvio de } \\
\text { e-mails. }\end{array}$ \\
\hline $\begin{array}{c}\text { Eficiência da } \\
\text { abordagem (EA) }\end{array}$ & Abord. & $\begin{array}{l}\text { Medir a eficiência } \\
\text { da abordagem } \\
\text { de um convênio } \\
\text { realizado. }\end{array}$ & $E A=\left(\frac{1}{\sum \text { emails }}\right) \times 100$ & $\begin{array}{l}\text { Número de e-mails } \\
\text { enviados durante } \\
\text { abordagem e followup } \\
\text { de um convênio } \\
\text { realizado. }\end{array}$ & $\begin{array}{l}\text { Número em } \\
\text { percentual da } \\
\text { eficiência dos e-mails } \\
\text { para a realização de } \\
\text { um convênio. }\end{array}$ \\
\hline $\begin{array}{l}\text { Efetividade do } \\
\text { contato (EC) }\end{array}$ & $\begin{array}{l}\text { Abord. } \\
\text { assin. } \\
\text { publ. }\end{array}$ & $\begin{array}{l}\text { Verificar a } \\
\text { efetividade dos } \\
\text { contatos iniciados. }\end{array}$ & $E C=\left(\frac{\sum \text { Convênios }}{\sum \text { Contatos }}\right) \times 100$ & $\begin{array}{l}\text { № de convênios } \\
\text { publicados no ano; } \\
\text { No de contatos iniciados } \\
\text { no ano. }\end{array}$ & $\begin{array}{l}\text { Percentual de } \\
\text { contatos iniciais que } \\
\text { se transformaram em } \\
\text { convênios publicados } \\
\text { durante o ano. }\end{array}$ \\
\hline $\begin{array}{l}\text { Quantidade de } \\
\text { convênios (QC) }\end{array}$ & Publ. & $\begin{array}{l}\text { Quantificar a } \\
\text { produção de } \\
\text { convênios realizados } \\
\text { por ano. }\end{array}$ & $Q C=\sum$ Convênios & $\begin{array}{l}\text { № de convênios } \\
\text { publicados no ano. }\end{array}$ & $\begin{array}{l}\text { Gráfico com o } \\
\text { número de convênios } \\
\text { publicados a cada } \\
\text { ano. }\end{array}$ \\
\hline $\begin{array}{c}\text { Tempo do } \\
\text { processo (TP) }\end{array}$ & Todos & $\begin{array}{l}\text { Medir o tempo total } \\
\text { do processo. }\end{array}$ & $\mathrm{TP}=\mathrm{DP}-\mathrm{DPC}$ & $\begin{array}{l}\text { DP: data de publicação; } \\
\text { DPC: data do primeiro } \\
\text { contato. }\end{array}$ & $\begin{array}{l}\text { Tempo (em dias) } \\
\text { necessário para } \\
\text { realização do processo } \\
\text { de convênio. }\end{array}$ \\
\hline $\begin{array}{l}\text { Tempo médio do } \\
\text { processo } \\
\text { (TMP) }\end{array}$ & Todos & $\begin{array}{l}\text { Medir o tempo } \\
\text { médio gasto com o } \\
\text { processo. }\end{array}$ & $T M P=\frac{\sum_{i}^{n} T P}{Q C}$ & $\begin{array}{l}\text { Tempo de processo de } \\
\text { cada convênio publicado } \\
\text { durante o ano; } \\
\text { Quantidade de convênios } \\
\text { publicados no ano. }\end{array}$ & $\begin{array}{l}\text { Tempo médio do } \\
\text { processo no ano. }\end{array}$ \\
\hline
\end{tabular}


a elaboração dos indicadores de desempenho de processo apresentados a seguir.

\subsection{Definição de indicadores}

Foram elaborados seis indicadores de desempenho (Quadro 1) a partir da necessidade de subsidiar o planejamento, análise e melhoria contínua na gestão do processo. Por se tratar de uma instituição pública e gratuita na qual os convênios precisam manter a gratuidade para os estudantes, entende-se que ao se tratar das dimensões tempo, capacidade e qualidade, a dimensão custos será indiretamente contemplada.

Dos seis indicadores propostos, quatro referem-se à fase de abordagem, pois de todas as fases envolvidas esta é a que o International Office tem maior autonomia e controle para a realização de melhorias e eventuais mudanças. Com esses indicadores, espera-se que o International Office consiga identificar:

- As fontes de indicações de convênios mais frequentes;

- 0 nível de eficiência em transformar contatos iniciados em convênios efetivos;

- Os principais focos de problemas entre o primeiro contato e a elaboração da minuta do convênio pronto (followup); e

- A produtividade geral em termos de convênios realizados no ano e o tempo médio gasto para a realização desses convênios.

\subsection{Implantação do processo modificado}

Um dos fatores centrais para a aplicação do BPM, que ocorre de fato e com sucesso, é o envolvimento das pessoas. No caso deste estudo, o envolvimento das pessoas ocorreu desde o início, uma vez que o estudo foi solicitado pelo próprio International Office e pela Comissão de Relações Internacionais. Por isso, os resultados e propostas do estudo foram apresentados e aprovados tanto pelo diretor da Comissão de Relações Internacionais da Escola de Negócios quanto pelo responsável do International Office. Tais propostas têm sido gradativamente implantadas.

As aprovações por parte dos departamentos já foram eliminadas, e os indicadores começaram a ser usados. Ambos são exemplos do que Jeston e Nelis (2006) chamam de pequenas vitórias na implantação do BPM. Porém, o mesmo não pode ser dito quanto às mudanças que envolvem a Assessoria Jurídica e a Comissão de Orçamento e Patrimônio. As melhorias em relação a esses setores dependem de mudanças institucionais e no sistema de informação institucional. Cabe, portanto, à Comissão de Relações Internacionais ou à própria Escola de Negócios sinalizar às instâncias superiores a necessidade dessas alterações.

\section{Considerações finais}

Durante o estudo, realizado em uma Escola de Negócios de IES pública brasileira, em um de seus campi, localizado no interior do estado de São Paulo, foi possível observar a existência de questões burocráticas da IES que não apenas interferem na agilidade do processo de realização de convênios, como também limitam a imediata aplicação das propostas de melhoria sugeridas.

Entretanto, o BPM demonstrou-se aplicável como instrumento de gestão e melhoria de processos. A aplicação inicial do BPM no processo de internacionalização de uma IES, a partir de um processo primário e crítico como a realização de convênios bilaterais, permitiu melhor compreensão do processo proporcionando a identificação de pontos críticos e propostas de melhorias. Uma aplicação mais ampla de BPM ocorrerá na medida em que a IES, a Escola de Negócios e o próprio International Office passem a utilizar o BPM em outros processos.

Como contribuições deste estudo podemos destacar:

- Aplicação inicial do BPM no contexto de prestação de serviços e, mais especificamente, em uma IES em seu processo de internacionalização;

- Mapeamento de um dos processos fundamentais na internacionalização de uma IES, o processo de convênios bilaterais, que pode ser utilizado como parâmetro por gestores educacionais que estejam buscando implantar ou ampliar a internacionalização no ensino superior;

- Simplificação e melhoria do processo de realização de convênios com redução do seu tempo de execução;

- Proposta de indicadores para a mensuração, controle e melhoria contínua do processo; e

- Apresentação dos primeiros passos na implantação do BPM, em um processo primário e crítico, inserido no processo de internacionalização de uma IES.

Sugere-se que em estudos posteriores seja ampliada a aplicabilidade do BPM para outros aspectos do processo de internacionalização de IESs.

\section{Referências}

AHMAD, H.; FRANCIS, A.; ZAIRI, M. Business process reengineering: critical success factors in higher education. Business Process Management Journal, v. 13, n.3, p. 451-469, 2007. http://dx.doi. org/10.1108/14637150710752344

ASSOCIATION OF BUSINESS PROCESS MANAGEMENT PROFESSIONALS - ABPMP. Guia para o gerenciamento de processos de negócio: corpo comum de conhecimento (BPM CBOK). versão 2.0. Chicago: Association of Business Process Management Professionals, 2009. Primeira liberação em português. 
BRASIL. Ministério do Desenvolvimento, Indústria e Comércio Exterior - MDIC. Termo de referência: internacionalização de empresas brasileiras. Brasília, 2009. Disponível em: <http://www.mdic.gov.br/portalmdic/sitio/interna/noticia. php?area=1Etnoticia=9508>. Acesso em: 26 abr. 2010.

GEREFFl, G. International trade and industrial upgrading in the apparel commodity chain. Journal of International Economics, v. 48, p. 37-70, 1999. http://dx.doi. org/10.1016/S0022-1996(98)00075-0

GONZALEZ, L. S. et al. Measurement in business processes: a systematic review. Business Process Management Journal, v. 16, n. 1, p. 114-134, 2010. http://dx.doi. org/10.1108/14637151011017976

JESTON, J.; NELIS, J. Business process management: practical guidelines to successful implementations. Oxford: Elsevier, 2006

KNIGHT, J. Cross-border education: not Just students on the move. International Educator, v. 15, n. 2, 2006.

KNIGHT, J. Updating the definition of internationalization. International Higher Education, n. 33, 2003.

KO, R. K. L.; LEE, S. S. G.; LEE, E. W. Business process management (BPM) standards: a survey. Business Process Management Journal, v. 15, n. 5, p. 744-791, 2009. http://dx.doi.org/10.1108/14637150910987937

KOHLBACHER, M. The effects of process orientation: a literature review. Business Process Management Journal, v. 16, n. 1, p. 135-152, 2010. http://dx.doi. org/10.1108/14637151011017985

KUJANSIVU, P.; LÖNNQVIST, A. Business process management as a tool for intelectual capital management. Knowledge and Process Management, v. 15, n. 3, p. 159-169, 2008. http://dx.doi.org/10.1002/kpm.307

LIMA, M. C.; MARANHÃO, C. M. S. A. 0 sistema de educação superior mundial: entre a internacionalização ativa e passiva. Avaliação, v. 14, n. 3, p.583-610, 2009.

McCORMACK, K. et al.A global investigation of key turning points in business process maturity. Business Process Management Journal, v. 15, n. 5, p. 792-815, 2009. http://dx.doi.org/10.1108/14637150910987946

MIURA, 1. K. O processo de internacionalização da Universidade de São Paulo: um estudo de três áreas de conhecimento. 2006. 365 f. Tese (Livre Docência)Faculdade de Administração, Economia e Contabilidade, Universidade de São Paulo, Ribeirão Preto, 2006.
NEAVE, G. Managing Higher Education International Cooperation. Referent Document UNESCO, 1992.

OBJECT MANAGEMENT GROUP - OMG. Business process model and notation (bpmn): FTF beta 1 for version 2.0. Neadham: OMG, 2009. Disponível em: HTTP://www. omg.org/spec/BPMN/2.0. Acesso em: 27 abr. 2010.

OLIVEIRA, S. B. Qualificando os processos de sua organização. In: VALLE, R.; OLIVEIRA, S. B. (Org.). Análise e modelagem de processos de negócio: foco na notação BPMN (Business Process Modeling Notation). São Paulo: Atlas, 2009.

OLIVEIRA, S. B.; ALMEIDA NETO, M. A. Análise e modelagem de processos. In: VALLE, R.; OLIVEIRA, S. B. (Org.) Análise e modelagem de processos de negócio: foco na notação BPMN - Business Process Modeling Notation. São Paulo: Atlas, 2009

PAIM, R. et al. Gestão de processos: pensar, agir e aprender. Porto Alegre: Bookman, 2009.

PAIM, R.; CAULLIRAUX, H.; CARDOSO, R. Process management tasks: a conceptual and practical view. Business Process Management Journal, v. 14, n. 5, p. 694-723, 2008. http://dx.doi.org/10.1108/14637150810903066

PALMBERG, K. Experiences of implementing process management: a multiple-case study. Business Process Management Journal, v. 16, n. 1, p. 93-113, 2010. http://dx.doi.org/10.1108/14637151011017967

RECKER, J. Opportunities and constraints: the current struggle with BPMN. Business Process Management Journal, v. 16, n. 1, p. 181-201, 2010.http://dx.doi. org/10.1108/14637151011018001

SEETHAMRAJU, R.; MARJANOVIC, 0. Role of process knowledge in business process improvement methodology: a case study. Business Process Management Journal, v.15, n. 6, p. 920-936, 2009.

SHETTY, A; RUDELL, F. Internationalizing the business program: a perspective of a small scholl. Journal of Education for Business, v. 78, n. 2, p. 103-110, 2002. http://dx.doi.org/10.1080/08832320209599706

TRKMAN, P. The critical success factors of business process management. International Journal of Information Management, v. 30, n. 2, p. 125-134, 2010. http:// dx.doi.org/10.1016/j.jijinfomgt.2009.07.003

UNESCO. Recueil de données mondiales sur l'éducation 2009: statistiques comparées sur l'éducationdans le monde. Montréal: Institut de Statistique de l'UNESCO, 2009.

\section{Process management applied to the establishment of international bilateral agreements in a brazilian public institution of high education Abstract}

The process of internationalization of higher education has been enhanced by the possibilities of globalization. Such process is characterized by its complexity and difficulties in management. Thus, Business Process Management (BPM) is the suggested management approach to complex processes like this. Therefore, this study aims to contribute through the evaluation and proposal of BPM applicability to the internationalization process of a public Brazilian Higher Education Institution (HEI). The research was limited to the process of establishment of international bilateral agreements of the School of Business in one of the Institution's campuses. The process of bilateral agreements was modeled in its current form. From the analysis of the existent model, a proposal for improvements was made and a new model was suggested, besides performance indicators.

\section{Keywords}

Internationalization of higher education. Business process management. Process modeling. 